\title{
Increasing incidence of hospitalisation for sport-related concussion in Victoria, Australia
}

\begin{abstract}
Caroline F Finch BSc(Hons), MSc, PhD NHMRC Principal Research Fellow and Professor

Angela J Clapperton M(Counsel), GradDipEdPsych, BSc(Behav) Research Fellow

Paul McCrory MB BS, PhD, FRACP NHMRC Practitioner Fellow and Associate Professor

1 Centre for Healthy and Safe Sport, University of Ballarat, Ballarat, VIC.

2 Victorian Injury Surveillance Unit, Monash niury Research Institute, Monash University, Melbourne, VIC

3 Florey Neurosciences Institute, University of Melbourne, Melbourne, VIC

c.finch@ballarat.edu.au
\end{abstract}

MJA 2013; 198: 1-4 doi: 10.5694/mjal2.11217

Online first 20/03/13

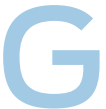
lobally, traumatic brain injury (TBI) is the leading cause of death and disability in children and adults and is involved in nearly half of all trauma deaths. ${ }^{1}$ In Australia, Europe and the United States, the estimated annual incidence of TBI requiring hospitalisation is 60-250 per 100000 population, with $80 \%-90 \%$ of cases categorised as mild TBI. ${ }^{2}$ For some young adults in the US, the annual incidence of emergency department presentations for TBI is reportedly as high as 760 per 100000 population. ${ }^{3}$ In Australia, limited population data are available, but one report estimated the direct hospital costs for all TBI in the 2004-05 financial year at \$184 million. 4

A subset of mild TBI is concussion, reflecting a complex pathophysiological process resulting from trauma to the brain. Common symptoms include headache, amnesia, confusion, blurred vision, dizziness, nausea, balance problems and fatigue. Loss of consciousness is reported in $10 \%-20 \%$ of cases. Most concussions resolve within a few days to weeks, but in some cases the symptoms can be prolonged. ${ }^{5-7}$ The estimated incidence of concussion varies between countries, but US census data suggest about 600 cases per 100000 population. $^{3}$ In 2004-05, of the 22710 Australia-wide hospital separations coded as TBI using the International statistical classification of diseases and related health problems, 10th revision, Australian modification (ICD-10-AM), ${ }^{8}$ $16.9 \%$ were concussions with no loss of consciousness and $64.2 \%$ were other TBI with some loss of consciousness. ${ }^{4}$

Injuries during sport account for about a fifth of all TBI cases, ${ }^{2}$ but as sport is included under several injury mechanism categories in routinely collected data, the precise incidence is unknown. This is particularly so in Australia, where there is no routine monitoring or reporting of sportrelated concussion. Data using ICD-9 coding suggest there are 1.6-3.8 million

\section{Abstract}

Objective: To describe trends in hospitalisation for sport-related concussion.

Design, setting and patients: Analysis of routinely collected hospital admissions data from all Victorian hospitals (public and private) over the 200203 to 2010-11 financial years for patients aged $\geqslant 15$ years with a diagnosis of concussion and an ICD-10-AM external cause activity code indicating sport.

Main outcome measures: Number and cost of hospitalisations; rate of hospitalisation per 100000 participants overall and for specific sports; and percentage change in frequency and hospitalisation rate per 100000 participants over 9 years.

Results: There were 4745 hospitalisations of people aged $\geqslant 15$ years for sportrelated concussion, with a total hospital treatment cost of $\$ 17944799$. The frequency of hospitalisation increased by $60.5 \%$ ( $95 \% \mathrm{Cl}, 41.7 \%-77.3 \%$ ) over the 9 years, but could only partially be explained by increases in sports participation, as the rate per 100000 participants also increased significantly, by $38.9 \%(95 \% \mathrm{Cl}, 17.5 \%-61.7 \%)$. After adjustment for participation, rates were highest for motor sports, equestrian activities, Australian football, rugby and roller sports. The greatest significant increases in rates were seen in roller sports, rugby, soccer and cycling.

Conclusions: The frequency and participation-adjusted rate of hospitalisation for sport-related concussion, both overall and across several sports, increased significantly over the 9 years. These findings, along with high levels of public concern, make prevention of head injury in sport a population health priority in Australia.

hospital presentations for sports and recreation-related head injury in the US annually. ${ }^{2}$ As sport-related concussions are not usually reported to doctors, this could underestimate the true incidence by a factor of six to $10 .^{9}$

As the incidence of sport-related concussion in Australia, especially at the population level, is unknown, we aimed to enumerate trends in the incidence of hospitalisation for sportrelated concussion in Victoria over a 9year period, along with estimating the total hospital costs. A secondary aim was to identify the specific sports with the highest frequency of hospitalisation for concussion and to examine trends in these sports over the same period. It is hoped that this information will be used to identify priority groups for population targeting of concussion prevention and management strategies.

\section{Methods}

The Victorian Injury Surveillance Unit is the repository for de-identified injury surveillance data in Victoria, outsourced by the Victorian Department of Health. Hospitalisation data relating to all admissions to public and private hospitals in Victoria for the 9 financial years from 2002-03 to 2010-11 were extracted from the Victorian Admitted Episodes Dataset (VAED). Data in the VAED are coded to the ICD-10-AM. ${ }^{8}$ We chose July 2002 as the start date to coincide with the introduction of the third edition of the ICD-10-AM, which introduced more than 200 codes for sporting activities.

From the VAED data, we selected patients aged $\geqslant 15$ years who had all of the following, as indicated by ICD10-AM codes:

- a principal diagnosis recorded as an injury (S00-T98)

- a concussive injury recorded anywhere in the diagnosis codes (S06.00S06.05)

- an unintentional external cause code (V00-X59)

- a sport or exercise activity code at the time of the incident (U50-U71).

We restricted our analysis to people aged $\geqslant 15$ years because appropriate 
published sports participation data were only available for this group. To minimise multiple counting of patients, transfers within and between hospitals and identifiable readmissions to the same hospital within 30 days were excluded.

Ethics approval for the study was obtained from the Human Research Ethics Committee at the Victorian Department of Health.

\section{Hospitalisation costs}

Each hospitalisation is assigned an Australian Refined Diagnosis Related Group (AR-DRG), which provides a clinically meaningful way of relating the types of hospital patients to the resources required by the hospital to treat them. The National Hospital Cost Data Collection produces average public hospital costs for each ARDRG, by state. We assigned the Victorian average costs to each hospitalisation for concussion according to its AR-DRG.

\section{Concussion rates and participation- adjusted trends}

We obtained sports participation numbers from the annual Exercise, Recreation and Sport Survey (ERASS) for each year from 2002 to $2010 .^{10}$ The ERASS is a joint initiative of the Australian Sports Commission and state and territory departments of sport and recreation. It collects information on the frequency, duration, nature and type of activities that people aged $\geqslant 15$ years participated in for exercise, recreation or sport during the previous 12 months. We calculated the annual number and rate of hospitalisations for sport-related concussion both overall and for individual sports, using the participation data as the denominator.

Trends in the annual rate of hospitalisation for sport-related concussion per 100000 participants aged $\geqslant 15$ years were computed using a loglinear regression model of the rate data, assuming a negative binomial distribution of cases. Statistics relating to the trend curves (ie, the slope and intercept) and their associated $P$ values were calculated using the regression model in SAS version 9.1 (SAS Institute). A trend was considered statistically significant if the $P$ of the regression slope was $<0.05$.

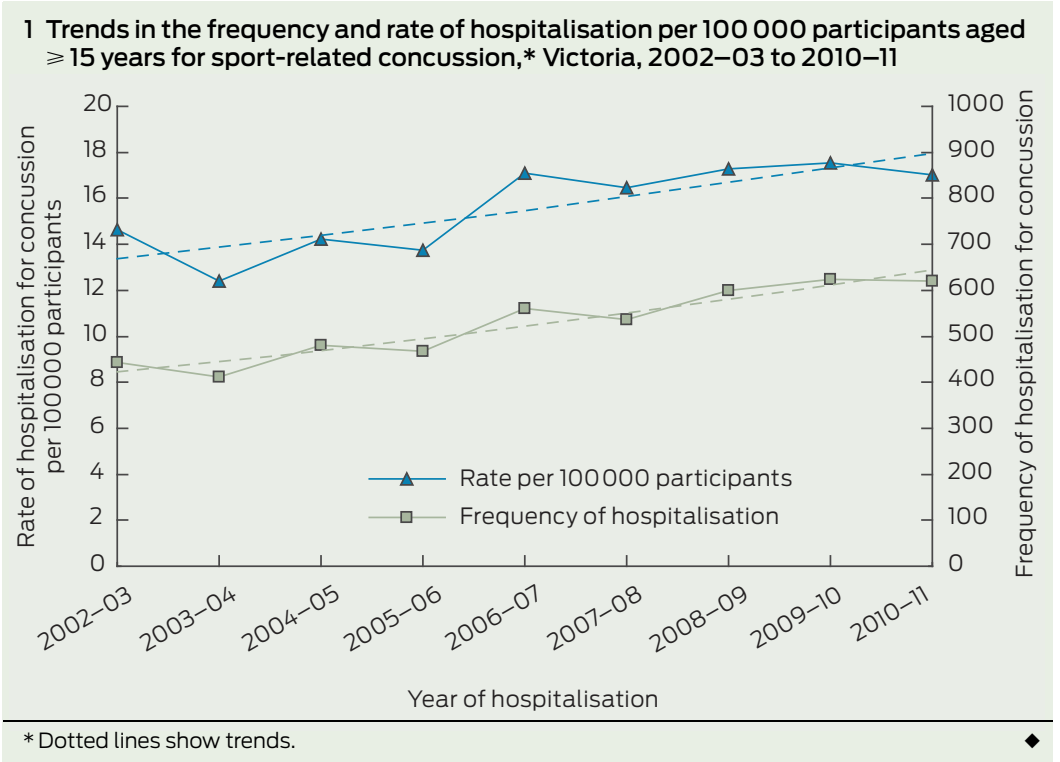

\section{Results}

Of the 28718 hospitalisations for concussion in people aged $\geqslant 15$ years in Victoria over the 9-year period, 4745 (16.5\%) were for sport-related concussion. The estimated total hospital cost of hospitalisations for sportrelated concussion over the 9 years was \$17944 799 (\$1 993867 per year), with a median cost per admission of $\$ 1583$ (range, $\$ 631$ to $\$ 190190$ ). Although the average hospital costs used to calculate these figures are specific to the public sector, only 94 hospitalisations $(2 \%)$ were in private hospitals.

The annual number of hospitalisations for sport-related concussion increased significantly by $60.5 \%$ (95\% CI, 41.7\%-77.3\%; $P<0.001$ ), from 443 in 2002-03 to 621 in 2010-11 (Box 1), corresponding to an average annual increase of $5.4 \%$ (95\% CI, $4.0 \%-6.6 \%$; $P<0.001)$. Over the same period, the rate of hospitalisation for concussion injury per 100000 participants also increased significantly, by 38.9\% (95\% CI, $17.5 \%-61.7 \% ; P<0.001$ ) (Box 1), an average annual increase of 3.7\% (95\% CI, $1.8 \%-5.5 \%$; $P<0.001)$. Thus, just over a third of the increase in hospitalisation can be explained by increases in reported sports participation.

The most common activities leading to hospitalisation (defined as accounting for $>50$ hospitalisations over the 9-year period) were: team ball sports (particularly the football codes), modes of active transportation, and snow-based adventure sports (Box 2). Together, the football codes accounted for 36.0\% (1709/ $4745)$ of all hospitalisations. The activities with the highest mean participation-adjusted rates of hospitalisation for concussion over the 9-year period were motor sports (181.8 per 100000 participants), equestrian activities (130.3/100 000) and Australian football (80.3/100 000) (Box 2).

Cricket was the only activity with a decrease in the rate of hospitalisation for sport-related concussion, but it was not statistically significant. The rate of hospitalisation for concussion injury increased in all other major sports and recreational activity groups, although the increases were only significant for roller sports, rugby, cycling and soccer.

\section{Discussion}

Our findings show that the number of patients with ICD-10-AM-coded sport-related concussion admitted to hospital in Victoria increased by $61 \%$ over the period 2002-03 to 2010-11. Much of this increase was independent of changes in sports participation, because the participation-adjusted hospitalisation rate also increased significantly by $39 \%$ over this period.

Head injuries sustained during participation in sport place a significant burden on the health care systems needed to assess and treat them; the 
2 Frequency, mean rate per 100000 participants, and trend of hospitalisation of people aged $\geqslant 15$ years for sport-related concussion, Victoria, 2002-03 to 2010-11

\begin{tabular}{|c|c|c|c|c|c|}
\hline Sports activity* & Frequency & $\begin{array}{l}\text { Mean rate }{ }^{\dagger} \text { over } \\
\text { 9-year period }\end{array}$ & $\begin{array}{l}\text { Estimated annual \% } \\
\text { change in rate }\end{array}$ & $\begin{array}{l}\text { Estimated \% change in } \\
\text { rate over } 9 \text {-year period }\end{array}$ & $P$ for trend \\
\hline Australian football ${ }^{\xi}$ & 1442 & 80.3 & $0.9 \%$ & $8.2 \%$ & 0.74 \\
\hline Cycling & 766 & 17.6 & $5.5 \%$ & $62.0 \%$ & 0.004 \\
\hline Motor sports & 674 & 181.8 & $0.5 \%$ & $4.6 \%$ & 0.86 \\
\hline Equestrian activities & 504 & 130.3 & $1.0 \%$ & $9.0 \%$ & 0.79 \\
\hline Soccer & 198 & 9.7 & $6.5 \%$ & $76.6 \%$ & 0.007 \\
\hline Ice and snow sports & 184 & 31.2 & $1.9 \%$ & $18.9 \%$ & 0.70 \\
\hline Basketball & 115 & 6.9 & $2.6 \%$ & $26.3 \%$ & 0.70 \\
\hline Roller sports 9 & 105 & 44.8 & $20.2 \%$ & $424.8 \%$ & $<0.001$ \\
\hline Rugby (all codes)** & 69 & 49.9 & $10.1 \%$ & $95.8 \%$ & $<0.001$ \\
\hline Netball & 55 & 3.6 & $8.0 \%$ & $100.5 \%$ & 0.31 \\
\hline Cricket & 51 & 3.0 & $-4.2 \%$ & $-31.8 \%$ & 0.53 \\
\hline All others & 582 & 3.8 & $6.7 \%$ & $80.0 \%$ & 0.003 \\
\hline Total & 4745 & 15.6 & $3.7 \%$ & $38.9 \%$ & $<0.001$ \\
\hline
\end{tabular}

* The specific sports activities listed are those with $>50$ hospitalisations for concussion in total over the 9 -year period. $\dagger$ Per 100000 participants aged $\geqslant 15$ years. $\ddagger$ For the trend analyses, yearly rates were computed using published participation denominator data for each year. $\$$ All "football unspecified" cases $(n=254)$ were included in the "Australian football" category on the presumption that patients playing soccer or rugby would specify they were playing these codes in Victoria. This may not be so for all players, and there may be some misclassification. 9 Roller sports includes inline skating, rollerskating, skateboarding and non-motor scooter riding. ** Data for all rugby codes combined cover only 7 years (2004-05 to 2010-11 financial years) as no published participation data were available for the first 2 years (there were an additional 13 hospitalisations for rugby-related concussion that occurred during 2002-03 and 2003-04). sport delivery systems responsible for providing safe sporting opportunities; and the individuals who sustain them. The short- and long-term consequences of concussion mean that potentially years of productive life are lost, and there are substantial economic costs for individuals, families and society.

In the US, substantial economic and societal effects of TBI have been reported, with an estimated 1.7 million people sustaining a TBI annually, associated with 1.4 million emergency room visits and 275000 hospitalisations. ${ }^{11}$ In the sporting context, the number of concussions reported to the National Collegiate Athletic Association increased significantly by $7 \%$ annually from the 1988-89 to 2003-04 US academic years. ${ }^{12}$ These data reflect a wide range of collegiate sports participation, and the increasing trends could reflect increasing concussion awareness, changes in player risk, or changes in data collection methodology. ${ }^{13,14}$ Increasing injury incidence seems not to be confined to Victoria and may reflect a longer-term increasing incidence of injury globally.

The reasons for the increasing trends of hospitalisation for concussion in our study are unknown. They could reflect, at least partially, changing health delivery system factors such as improved detection of concussion and its diagnosis in the hospital setting. Some of the increase could be related to greater awareness of concussion leading to more people presenting to hospitals for treatment. However, as the data here relate only to patients who were hospitalised, this presentation bias is expected to be minimal over time. It is not known if patients with concussion treated in emergency departments (but not admitted), by general practitioners or by sports medicine practitioners follow the same trends.

Sports delivery factors could also contribute to the increasing trends. For example, increased competitiveness may lead to faster game speeds and higher-intensity activity, and hence increased forces of collision that lead to concussive impacts. As athletes get bigger, stronger and faster, and there are attempts to increase game speeds for spectator enjoyment, it is logical that the forces associated with collisions would also increase in magnitude. There is currently no effective headgear that prevents concussions, so more collisions with more force would be expected to increase the number of concussions. Other ways to prevent concussion are rule changes and game modifications, better education of coaches and players, and adherence to return-to-play guidelines after a previous head injury.

Although the football codes are often thought to be the source of most sport-related concussion, ${ }^{15}$ case-series reports of ICD-10-AMcoded hospitalisations for injury have found that concussion is also highly associated with equestrian activities, soccer, cricket, netball and martial arts. ${ }^{4,16}$ Nonetheless, based on a comparison of results from epidemiological studies of team sports with variable definitions of concussion, Australia's high-participation football codes may be associated with a concussion risk 10-15 times higher than that for American football. ${ }^{17-19}$ This difference likely reflects differences in injury mechanisms, speeds at which the games are played, and the personal protective equipment used. In our study, football accounted for just over a third of all concussion cases. Over the 9-year period, the participation-adjusted rates of hospitalisation increased significantly by $77 \%$ in soccer and by $96 \%$ in rugby, but nonsignificantly by $8 \%$ in Australian football, perhaps reflecting greater attention to concussion prevention in the latter than in other football codes. These increases support priority attention being given to preventing concussion across all football codes.

Our data also show that sportrelated concussion is not just a problem for football. In fact, the highest participation-adjusted rates of hospitalisation were for motor sports and equestrian activities, where higherimpact speeds and greater fall distances are more likely to lead to concussion. The greatest increase over the 9-year period was in roller sports; the reasons for this are unclear. These findings confirm the US experience of concussion occurring in many sports, ${ }^{14,20}$ and emphasises that a focus on football codes alone would not prevent most concussions.

Our study has some limitations. It assumes that the diagnosis of concussion has been made correctly and that all cases have been identified by the ICD-10-AM coding. At least one study has shown misdiagnosis of head injury in emergency departments, ${ }^{21}$ and if this also occurs for hospital admissions, then the rates in our study would under-enumerate the 
true rate of hospitalisation for sportrelated concussion. In any case, the number of sport-related concussions is almost certainly underestimated because the only way to identify a sport in the ICD-10-AM is through the activity codes, which are known to be underused. ${ }^{22}$ Also, the sports participation data do not take into account the frequency of participation, and it may be that people who play more sport at higher intensities or more regularly are the people most at risk of concussion.

While only relating directly to one state, our data clearly demonstrate that sport-related concussion is a significant and increasing public health burden. Our findings are an underestimate of the true burden of sportrelated concussion because: a) they are only based on patients requiring hospitalisation, and most patients with concussion would not require hospitalisation; b) the number of hospitalisations is almost certainly an underestimate because of limitations in the available data; c) they only include direct hospital costs, and the indirect morbidity costs of injury are known to be at least as much as these; and d) there is no assessment of any adverse long-term health outcomes. Even when injured players sustain loss of consciousness, most do not attend a hospital for treatment. If the underreporting of incident cases was up to 10 -fold, ${ }^{9}$ the real number of sport-related concussions could be 47450 over the 9-year period, potentially costing the Victorian community about $\$ 20$ million annually.

The most recent international consensus statement on the management of concussion in sport strongly argued that there is an immediate need to develop guidelines, education resources and other health promotion approaches for preventing head injury and its adverse outcomes across all sports with a risk of serious head injury. ${ }^{7}$ Anecdotally, there are high levels of public concern about the risk of head injury in sport, and public misinformation about its assessment, management and prevention. ${ }^{23,24}$ Our findings that a large number of head injuries occur annually and that trends in participation-adjusted incidence rates are increasing make the prevention of head injury in sport a population health priority.

Acknowledgements: This study was partially funded by a grant from Sport and Recreation Victoria (SRV) within the Victorian Department of Planning and Community Development, and from funding from the International Olympic Committee (IOC). Caroline Finch was supported by a National Health and Medical Research Council (NHMRC) Principal Research Fellowship (ID: 565900), and Paul McCrory by an NHMRC Practitioner Fellowship. Angela Clapperton was supported by the Victorian Injury Surveillance Unit's core grant from the Victorian Department of Health.

Competing interests: Caroline Finch receives, or has previously received, competitive research funding from the following bodies for research into concussion or head injury in sport and its prevention: NHMRC, Australian Research Council (ARC), IOC, International Rugby Board (IRB), Australian Football League Research Board (AFLRB), Australian Rugby Union, SRV and the Victorian Health Promotion Foundation (VicHealth). Paul McCrory currently receives financial research support from the NHMRC, University of Melbourne, IOC, SRV and Eastern Health; his previous competitive grant funding includes the ARC, IRB, University of Melbourne, University of Otago, National Hockey League (US), VicHealth, AFLRB, Royal Australasian College of Surgeons, and the Australian Sports Commission. He has received travel funding from the Medical Commission of the IOC, the Fédération Internationale de Football Association (FIFA), the American Academy of Neurology and the Jockey Club (UK). He receives book royalties from McGraw-Hill and from 2001 to 2008 was employed by the BMJ Publishing Group. He has conducted clinical drug trials on antimigraine (Glaxo Wellcome, Janssen-Cilag, Novartis, Parke-Davis; Schering) and antispasticity drugs (Ipsen) through the Eastern Clinical Research Unit in Melbourne. This drug trial work has not involved any financial payment to him directly. He received consultancy fees in 2010 from Axon Sports (US) for the development of educational material (which was not renewed) and has received support since 2005 from CogState Inc for research costs and the development of educational material. He is a cofounder and shareholder in two biomedical companies (involved in e-health and compression garment technologies) but does not hold any individual shares in any company related to concussion or brain injury assessment or technology. Angela Clapperton has no relevant disclosures.

Received 2 Aug 2012, accepted 3 Feb 2013.

1 World Health Organization. Neurological disorders: public health challenges. Geneva: WHO, 2006. http://www.who.int/mental health/neurology/neurodiso/en/index.html (accessed Feb 2012).

2 Langlois JA, Rutland-Brown W, Wald MM. The epidemiology and impact of traumatic brain injury: a brief overview. J Head Trauma Rehabil 2006; 21: 375-378

3 Centers for Disease Control and Prevention (US). Incidence of traumatic brain injury in the United States, 2002 and 2003 updated data tables. Atlanta, Ga: CDC, 2007. http://www.cdc.gov/ ncipc/pub-res/tbi_in_us_04/TBI_Incidents.htm (accessed Sep 2012).

4 Helps Y, Henley G, Harrison JE. Hospital separations due to traumatic brain injury, Australia 2004-05. Canberra: AlHW, 2008. (AlHW Cat. No. INJCAT 116; Injury Research and Statistics Series No. 45.) http://www.aihw. gov.au/publication-detail/?id=6442468147 (accessed Feb 2012).

5 Macciocchi SN, Barth JT, Alves W, et al. Neuropsychological functioning and recovery after mild head injury in collegiate athletes. Neurosurgery 1996; 39: 510-514.

6 Echemendia RJ, Putukian M, Mackin RS, et al. Neuropsychological test performance prior to and following sports-related mild traumatic brain injury. Clin J Sport Med 2001; 11: 23-31.

7 McCrory P, Meeuwisse W, Johnston K, et al. Consensus statement on concussion in sport 3rd international conference on concussion in sport held in Zurich, November 2008. Clin J Sport Med 2009; 19: 185-200.

8 National Centre for Classification in Health. International statistical classification of diseases and related health problems, 10th revision, Australian modification (ICD-10-AM). 5th ed. Sydney: National Centre for Classification in Health, 2006.

9 Delaney JS, Lacroix VJ, Gagne C, Antoniou J. Concussions among university football and soccer players: a pilot study. Clin J Sport Med 2001; 11: 234-240.

10 Standing Committee on Recreation and Sport Participation in exercise, recreation and sport annual reports 2002-2010. State and territory tables for Victoria. Canberra: Australian Sports Commission, 2012. http://www.ausport.gov.au/ information/casro/ERASS/erass_past_reports (accessed Sep 2012)

11 Faul M, Xu L, Wald MM, Coronado VG. Traumatic brain injury in the United States: emergency department visits, hospitalizations and death 2002-2006. Atlanta, Ga: Centers for Disease Control and Prevention, National Center for Injury Prevention and Control, 2010. http://www.cdc. gov/TraumaticBrainlnjury/tbi_ed.html (accessed Mar 2012).

12 Hootman JM, Dick R, Agel J. Epidemiology of collegiate injuries for 15 sports: summary and recommendations for injury prevention initiatives. J Athl Train 2007; 42: 311-319.

13 Laker SR. Epidemiology of concussion and mild traumatic brain injury. PM R 2011; 3 (10 Suppl 2): S354-S358.

14 Daneshvar DH, Nowinski CJ, McKee AC, Cantu RC The epidemiology of sports-related concussion. Clin Sports Med 2011; 30: 1-17.

15 Gilbert F, Partridge BJ. The need to tackle concussion in Australian football codes. Med J Aust 2012; 196: 561-563.

16 Finch C, Boufous S, Dennis R. Sports/leisure injury hospitalisation episodes in NSW, 2003-2004: sociodemographic and geographic patterns and sport-specific profiles. Sydney: NSW Injury Risk Management Research Centre, 2007. http:// www.irmrc.unsw.edu.au/documents/irmrc SportsInjuryReport2-8-07forweb.pdf (accessed Jan 2013).

17 Braham R, Finch CF, McCrory P. The incidence of head/neck/orofacial injuries in non-elite Australian football. J Sci Med Sport 2004; 7 : 451-453.

18 McIntosh AS, McCrory P, Finch CF, Wolfe R. Head, face and neck injury in youth rugby: incidence and risk factors. Br J Sports Med 2010; 44: 188-193.

19 Hollis SJ, Stevenson MR, McIntosh AS, et al. Mild traumatic brain injury among a cohort of rugby union players: predictors for time to injury. $\mathrm{Br}\rfloor$ Sports Med 2011; 45: 997-999.

20 Marar M, Mcllvain NM, Fields SK, Comstock RD. Epidemiology of concussions among United States high school athletes in 20 sports. Am J Sports Med 2012; 40: 747-755.

21 Powell JM, Ferraro JV, Dikmen SS, et al. Accuracy of mild traumatic brain injury diagnosis. Arch Phys Med Rehabil 2008; 89: 1550-1555.

22 Finch CF, Boufous S. Do inadequacies in ICD-10AM activity coded data lead to underestimates of the population frequency of sports/leisure injuries? Inj Prev 2008; 14: 202-204.

$23 \mathrm{McCrory} P$. The eighth wonder of the world: the mythology of concussion management. $\mathrm{Br}$ J Sports Med 1999; 33: 136-137.

24 Ahmed OH, Sullivan SJ, Schneiders AG, McCrory PR. Concussion information online: evaluation of information quality, content and readability of concussion-related websites. Br J Sports Med 2012; 46: 675-683. 